
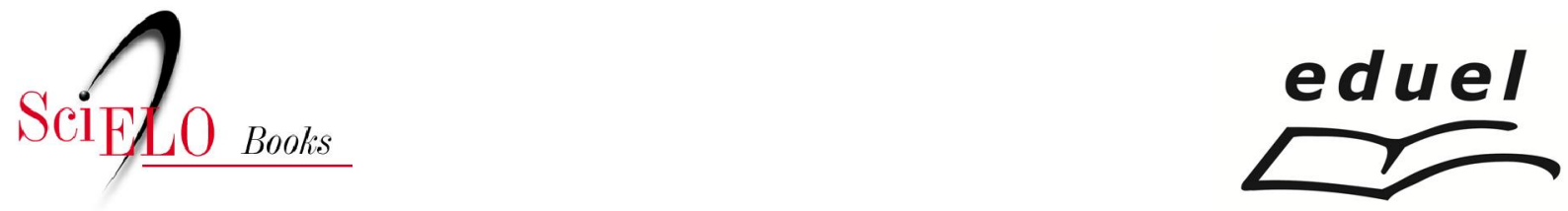

\title{
Habilidades motivacionais
}

\author{
Sandra Odebrecht Vargas Nunes \\ Márcia Regina Pizzo de Castro
}

NUNES, SOV., and CASTRO, MRP. Habilidades Motivacionais. In NUNES, SOV., and CASTRO, MRP., orgs. Tabagismo: Abordagem, prevenção e tratamento [online]. Londrina: EDUEL, 2011. pp.

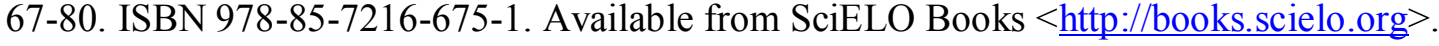

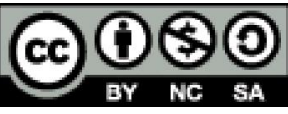

All the contents of this work, except where otherwise noted, is licensed under a Creative Commons Attribution-Non Commercial-ShareAlike 3.0 Unported.

Todo o conteúdo deste trabalho, exceto quando houver ressalva, é publicado sob a licença Creative Commons Atribuição Uso Não Comercial - Partilha nos Mesmos Termos 3.0 Não adaptada.

Todo el contenido de esta obra, excepto donde se indique lo contrario, está bajo licencia de la licencia Creative Commons Reconocimento-NoComercial-CompartirIgual 3.0 Unported. 

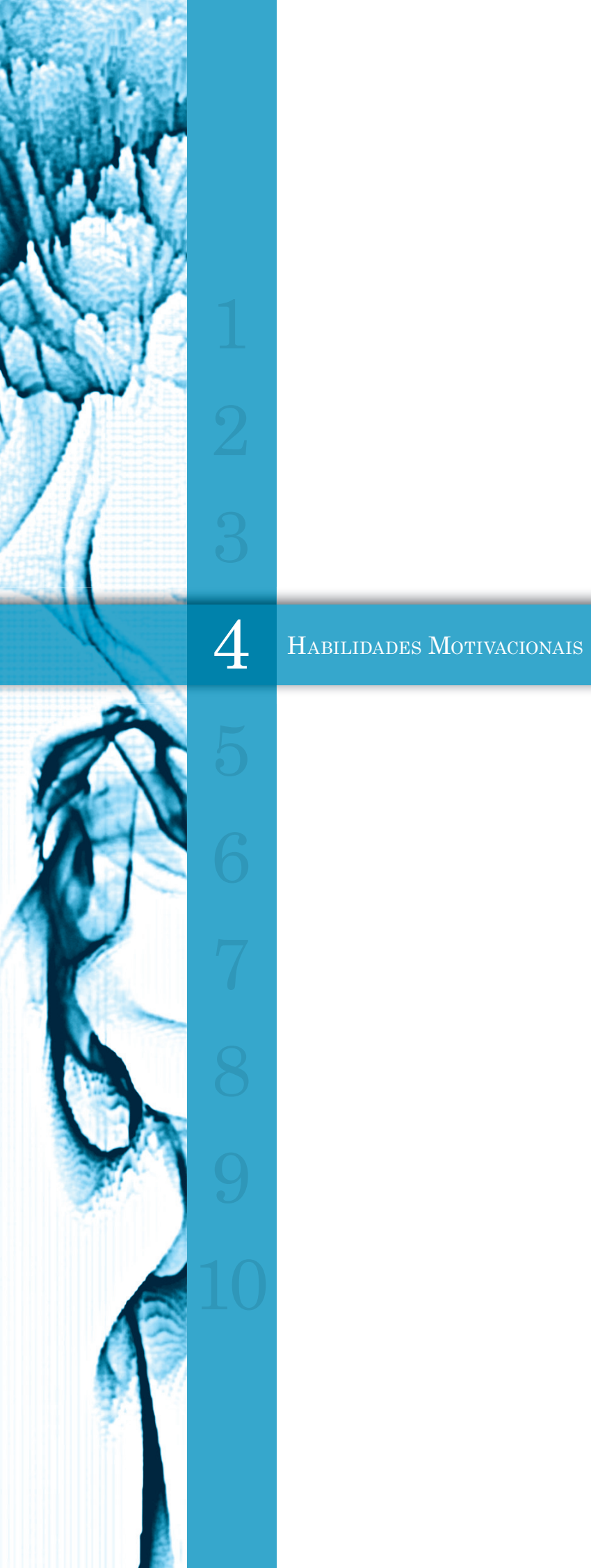


\section{Habilidades Motivacionais}

Sandra Odebrecht Vargas Nunes Márcia Regina Pizzo de Castro

\section{AS HABILIDADES MOTIVACIONAIS NA ABORDAGEM DO TABAGISTA}

As habilidades motivacionais são técnicas para evocar no paciente as suas boas motivações para fazer mudanças comportamentais no interesse de sua própria saúde. (ROLLNICK; MILLER; BUTLER, 2008). Na abordagem do tabagista, o profissional da saúde estimula-o a adotar hábitos saudáveis, instrumentalizando-o com estratégias baseadas na entrevista motivacional.

A entrevista motivacional (EM) é uma abordagem criada para auxiliar as pessoas a reconhecer e fazer algo a respeito de seus problemas presentes e potenciais. Ela é particularmente útil com pessoas que relutam em mudar e que são ambivalentes quanto à mudança. Pretende ajudar a resolver a ambivalência e colocar a pessoa em movimento, no caminho para a mudança. (MILLER; ROLLNICK, 2001). A EM atua ativando a própria motivação dos pacientes para a mudança e a adesão ao tratamento. A motivação para mudar é maleável e é formada principalmente no contexto dos relacionamentos. (ROLLNICK; MILLER; BUTLER, 2008).

Essa abordagem, que junta várias abordagens já existentes, tais como a terapia centrada no cliente e terapias breves, acrescentando alguns novos conceitos, tem como objetivo principal promover a mudança de comportamento.

As estratégias da entrevista motivacional são mais persuasivas do que coercitivas, mais encorajadoras do que argumentativas. O terapeuta busca criar uma atmosfera positiva que conduza à mudança. A meta final é aumentar a motivação intrínseca do paciente, de modo que a mudança venha de dentro, em vez de ser imposta de fora. Quando tal abordagem é corretamente utilizada, é o paciente quem apresenta os argumentos para a mudança, mais 
do que o terapeuta. A EM emprega uma variedade de estratégias, algumas derivadas da terapia centrada no paciente, para chegar a isso. $\mathrm{O}$ entrevistador motivacional trabalha com uma forte noção de objetivo e com estratégias para atingir tal fim; além disso, deve contar com uma boa noção de timing para intervir de maneiras específicas em momentos incisivos. (MILLER; ROLLNICK, 2001).

A motivação para o tratamento pode ser considerada um componente crítico em intervenções destinadas a mudar comportamentos relacionados ao consumo de álcool e outras drogas. A classificação dos pacientes em "estágios de mudança" pode ser uma ferramenta útil para organização e aperfeiçoamento dos programas de tratamento. (OLIVEIRA; MALBERGIER, 2003).

A EM baseia-se em dois conceitos. O primeiro é o de ambivalência que, nesse contexto, não significa apenas a relutância a fazer algo, mas sim a experiência de um conflito psicológico para decidir entre dois caminhos diferentes. Os dependentes de tabaco, quando buscam tratamento, geralmente o fazem com conflitos, com aquilo que chamamos de motivação flutuante, isto é, eles querem fazer algo a respeito do seu comportamento mas, ao mesmo tempo, também não querem. No caso dos fumantes, por exemplo, o conflito seria entre continuar fumando e parar de fumar. Ambivalência quanto à mudança de comportamento é difícil de resolver, porque cada lado do conflito tem seus benefícios e seus custos. Por ser a EM uma técnica desenvolvida para lidar com a dependência, temse como uma das suas metas principais a constatação e a resolução da ambivalência.

O segundo conceito é o de prontidão para a mudança, baseada no modelo de estágios de mudança, desenvolvido por Prochaska e Diclemente (1982). Tendo como base o conceito de motivação como um estado de prontidão ou vontade de mudar (como mencionado anteriormente, um estado interno mutável de acordo com fatores externos), esse modelo acredita que a mudança se faz mediante um processo e, para tal, a pessoa passa por diferentes estágios. A primeira forma de mostrar esse processo foi por meio de uma roda. São necessárias habilidades diferentes ao se trabalhar nos estágios da contemplação e da ação. 
A maneira como falamos com os pacientes sobre a sua saúde pode influenciar substancialmente sua motivação pessoal para mudar o seu comportamento. Rollnick, Miller e Butler (2008) propõem quatro princípios orientadores descritos abaixo:

\section{1 - Resistência ao reflexo de consertar as coisas;}

Relacionado à necessidade dos profissionais da saúde de prevenir o mal e promover o bem-estar. O problema é que essa inclinação inicial tem um efeito paradoxal. A razão não é que os pacientes sejam fracassados, resistentes, preguiçosos ou agarrados a uma nociva negação. Em vez disso, resistir à persuasão é uma tendência humana. Isso é particularmente verdadeiro quando se é ambivalente em relação a alguma coisa.

\section{2・ Entenda as motivações do seu paciente;}

Pois são elas, e não as suas, que são mais prováveis de desencadear a mudança de comportamento. Você deve perguntar aos pacientes por que eles gostariam de fazer uma mudança, e como poderiam fazê-la, no lugar de dizer a eles o que deveriam fazer.

\section{3• Escute o seu paciente;}

Porque os profissionais da saúde que desejam mudança de comportamento deverão lembrar que as respostas estarão dentro do próprio paciente, e é necessário escutá-los para encontrá-las.

\section{Fortalecendo o paciente;}

Os profissionais da saúde podem ajudá-lo a ser ativo e a explorar seus próprios recursos entendendo o porquê e como da mudança.

\section{OS ESTÁGIOS DE MUDANÇA DE COMPORTAMENTO}

Os estágios foram descritos por Prochaska e Diclemente (1982), fornecendo uma maneira útil para o entendimento de como as pessoas mudam seu comportamento e para avaliar o quanto a 
pessoa está disposta a mudar um comportamento de risco para outro, de preservação da saúde.

O ponto de partida para o processo de mudança é o estágio 1 . Nesse estágio, a pessoa ainda não está considerando a possibilidade de mudança (pré-ponderação ou pré-contemplação). Quando a pessoa é abordada e diz-se a ela que há um problema, ela pode ficar mais surpresa do que na defensiva. Os pré-ponderadores raramente se apresentam para tratamento. O objetivo, nesse estágio, é aumentar a percepção do paciente sobre riscos e problemas em relação ao tabagismo e motivá-lo a para pensar em mudança. De um modo geral a pessoa, nesse estágio, sequer encara o seu comportamento como um problema, podendo ser considerada resistente ou em negação.

As questões abordadas no estágio de pré-contemplação que motivam a pensar em mudança segundo, Zimmerman, Olsen e Bosworth (2000), são:

1 $\quad$ O que você acha que poderá acontecer se você continuar com o seu problema?

2. O que mais teme que possa acontecer, se não fizer a mudança?

3• Você já tentou mudar alguma vez? O que aconteceu?

Uma vez que alguma consciência do problema tenha surgido, a pessoa entra em um período caracterizado pela ambivalência, ou seja, no estágio de contemplação ou ponderação. Nele, a pessoa considera a mudança ou a rejeita, pensando em diminuir ou parar com o comportamento de risco. O objetivo é encorajá-las a falar sobre as razões e as barreiras para a mudança. Uma ferramenta útil, nesse estágio, é comparar a ambivalência do comportamento de risco a uma balança, e pesar as razões para mudar e as razões para continuar na mesma situação. O contemplador considera a mudança, mas ao mesmo tempo a rejeita, e é nessa fase que a ambivalência, estando no seu ápice, deve ser trabalhada para possibilitar um movimento rumo à decisão de mudar. Outra estratégia é saber as 
vantagens e desvantagens a curto e a longo prazo do comportamento de risco.

As questões abordadas no estágio de contemplação que motivam a pensar em mudança, segundo Zimmerman, Olsen e Bosworth (2000), são:

- $\quad$ Por que você deseja mudar agora?

- Quais as razões para a mudança?

- Quais os melhores resultados que você pode imaginar se fizesse uma mudança?

- Quais as barreiras para você realizar a mudança?

- Se você decidir fazer uma mudança, quais são suas expectativas para o futuro?

- Quem poderia lhe ajudar?

- Quais as coisas que funcionaram para você em outras ocasiões?

- Quais as suas necessidades para a mudança?

Uma vez trabalhada a ambivalência, a pessoa pode passar para o estágio de preparação ou determinação, onde ela está pronta para mudar e compromissada com a mudança. Faz parte desse estágio aumentar a responsabilidade pela mudança e elaborar um plano específico de ação. No estágio da preparação ou determinação, o terapeuta deve ajudar a pessoa a determinar a melhor linha de ação a ser seguida na busca da mudança.

O estágio seguinte é o de ação, onde a pessoa já muda e usa a terapia como um meio de assegurar-se do seu plano, para ganhar autoeficácia e, finalmente, para criar condições externas para a mudança No estágio da ação, o terapeuta deverá ajudar o paciente a dar passos rumo à mudança. As intervenções, nesse estágio, incluem: negociar conjuntamente as metas para mudar um comportamento de dependência do tabaco; sugerir estratégias que o paciente escolheria para ajudá-lo a reduzir ou parar seu 
comportamento de risco; ajudá-lo a identificar as situações de risco de recaída, como estresse, condicionamentos, lapsos e recompensas; dar apoio para que ele escolha suas estratégias de ação.

O grande teste para comprovar a efetividade da mudança seria a estabilidade nesse novo estado por anos que, no processo de mudança, chama-se manutenção. O estágio da manutenção do novo comportamento deve identificar e utilizar estratégias de prevenção de recaídas. As pessoas que estão tentando manter o comportamento mudado necessitam ser encorajadas a continuar o padrão atual e a identificar as situações e o manejo dessas situações.

Porém, deve-se ter em conta que, uma vez atingida alguma mudança, não significa que a pessoa se manterá nesse estágio: muitas pessoas acabam recaindo e tendo que recomeçar o processo. Nem sempre recomeçam pelo estágio inicial. Muitas pessoas passam inúmeras vezes pelas diferentes etapas do processo para chegar ao término, isto é, uma mudança mais duradoura.

A recaida é um aspecto essencial a ser entendido quando se fala em mudança de hábito nas dependências. No estágio de recaída, a desesperança costuma ser frequente. É preciso orientar o fato de que a recaída faz parte do tratamento. O profissional da saúde deverá ajudar a renovar os processos de ponderação, determinação e ação, sem desvalorização, proporcionando motivação para recomeçar.

Os tabagistas estão, de $10 \%$ a $15 \%$, na fase da ação; aproximadamente $30 \%$ a $40 \%$ estão na fase de contemplação e de $50 \%$ a $60 \%$, na fase de pré-contemplação. (PROCHASKA; DICLEMENTE; NORCROSS, 1992).

\section{OS COMPONENTES DA ENTREVISTA MOTIVACIONAL}

Os componentes da entrevista motivacional que objetiva ajudar às pessoas a moverem-se nos estágios de mudanças estão sumarizadas no quadro 6 . O que as motiva para a mudança e para o tratamento segundo Miller e Rollnick (2001), pode ser apresentado em blocos de construção: 
oferecer ORIENTAÇÃO

remover BARREIRAS

proporcionar ESCOLHAS

diminuir 0 aspecto DESEJÁVEL do comportamento

praticar EMPATIA

proporcionar FEEDBACK

esclarecer OBJETIVOS

Quadro 6- Componentes da entrevista motivacional.

Oferecer Orientação - Um elemento que estimula a mudança é uma orientação clara. Os conselhos por si só provavelmente não são suficientes para induzir à mudança na maioria dos indivíduos, mas a influência de uma orientação clara e compassiva não deve ser desprezada.

Remover Barreiras - Identificação e remoção das barreiras para as mudanças. As principais barreiras têm a ver com acesso ao tratamento ou outras estratégias de mudança.

Proporcionar Escolhas - Oferecer aos pacientes uma escolha entre abordagens alternativas pode diminuir a resistência e a desistência. Além disso, pode melhorar tanto a aderência aos tratamentos quanto o seu resultado. Poucas pessoas gostam que lhes digam o que fazer, ou que sejam forçadas a tomar determinada atitude. De fato, pode surgir resistência se a pessoa perceber que sua liberdade está sendo limitada ou ameaçada.

Diminuir o aspecto Desejável do comportamento ocorre na fase de contemplação, quando a pessoa está considerando os custos e os benefícios da mudança em relação aos méritos de continuar como antes. É como se houvesse uma balança motivacional entre os fatores favoráveis ao status quo e aqueles favoráveis à mudança. É seguro presumir que um padrão de comportamento persistente, apesar de suas consequências negativas, é mantido por incentivos 
positivos. Uma importante tarefa motivacional é identificar os incentivos positivos para a manutenção do comportamento.

Praticar a Empatia é uma habilidade específica para que haja compreensão dos significados da outra pessoa pelo uso da escuta reflexiva. Requer atenção aguçada a cada nova afirmação do paciente e a geração contínua de hipóteses em relação ao significado subjacente.

Proporcionar Feedback (retorno) - O conhecimento claro sobre a situação presente é o elemento da motivação para a mudança.

Esclarecer Objetivos é o estabelecimento de metas definidas que facilitam a mudança.

Ajudar Ativamente significa estar ativa e afirmativamente interessado no processo de mudança do paciente. A mudança é uma decisão do paciente, mas o terapeuta pode exercer grande influência sobre a tomada de decisão.

\section{OS PRINCÍPIOS DA ENTREVISTA MOTIVACIONAL}

A entrevista motivacional é uma interação do tipo diretiva, centrada no cliente, e que objetiva ajudar as pessoas a resolverem suas ambivalências sobre o uso do tabaco e moverem-se através dos estágios de mudança. Os cinco princípios da entrevista motivacional estão sumarizados no quadro 7. A entrevista motivacional é uma abordagem para ajudar a pessoa a reconhecer e fazer algo a respeito do seu comportamento. Nessa abordagem, é a pessoa quem apresenta seus argumentos para a mudança mais do que o terapeuta. Seus cinco princípios básicos são: expressar empatia, desenvolver discrepância, evitar argumentação, acompanhar a resistência e estimular a autoeficácia. 


\begin{tabular}{|c|l|}
\hline 1 & expressar EMPATIA \\
\hline 2 & desenvolver DISCREPÂNCIA \\
\hline 3 & evitar CONFRONTAÇÃO \\
\hline 4 & acompanhar a RESISTÊNCIA \\
\hline $\mathbf{5}$ & promover a AUTOEFICÁCIA \\
\hline
\end{tabular}

Quadro 7 - Os Princípios da entrevista motivacional.

Fonte: World Health Organization (2002b).

Expressar empatia é a capacidade de construção de aliança terapêutica conseguida pela escuta reflexiva e respeitosa e o desejo de compreender as esperanças e os receios do paciente. A "aceitação" dos limites do paciente facilita a ocorrência para mudança comportamental

Desenvolver discrepância é a meta de confrontar a pessoa com sua realidade desagradável, ou seja, uma discrepância entre seu comportamento atual e suas metas amplas na vida: entre onde está e aonde que chegar. Em geral, as pessoas têm como meta a saúde, o sucesso, a felicidade da família e uma autoimagem positiva. Quando seu comportamento atual é confrontado com isso, é provável que a mudança aconteça. As pessoas, com frequência, são mais persuadidas pelo que ouvem de si mesmas do que pelo que os outros lhe dizem. (BORDIN; FIGLIE; LARANJEIRA, 2004).

Evitar a confrontação, isto é, confrontações diretas. Para tal, é necessário ter em mente: discussões são contraprodutivas e suscitam defesas; defender-se gera resistência e essa resistência por parte do cliente é um sinal para o terapeuta mudar de estratégias. O princípio-chave da entrevista motivacional é aceitar que a ambivalência e a resistência para a mudança são normais, e devese levar o paciente a considerar novas informações e perspectiva em relação ao seu uso do tabaco. Quando o paciente expressar resistência, o profissional da saúde deve reestruturar o assunto e devolvê-lo ao paciente sem confrontação.

Acompanhar a Resistência. É preciso ter em mente que as percepções do paciente podem mudar, que novas perspectivas 
são mais bem recebidas quando não são impostas e que a própria pessoa é uma rica fonte de soluções de problemas. Deve-se fluir com a resistência, ao invés de enfrentá-la. Para tal é importante saber reconhecer o momento do cliente e saber usá-lo (ao invés de ir contra ele); ter em mente que as percepções do cliente podem mudar (principalmente se forem de relutância ao tratamento, ao contato terapêutico ou mesmo à mudança propriamente dita), se o terapeuta estiver bem preparado para fazê-lo; novas perspectivas são bem recebidas, mas não devem ser impostas; o cliente é uma rica fonte para possíveis soluções de problemas. (BORDIN; FIGLIE; LARANJEIRA, 2004).

Autoeficácia é a crença de uma pessoa em sua capacidade de realizar ou de ter êxito em uma tarefa específica. Ela pode ser considerada como elemento-chave na motivação para mudança e bom indicador de resultados de tratamento. (MILLER; ROLLNICK, 2001). Promover a autoeficácia é proporcionar a crença da própria pessoa em sua habilidade de enfrentar uma tarefa ou um desafio.

\section{HABILIDADES ESPECÍFICAS}

A entrevista motivacional utiliza de cinco habilidades para ajudar o paciente a explorar suas ambivalências sobre o uso de substâncias e a clarificar as razões para reduzir e parar com o uso. As cinco habilidades específicas estão sumarizadas no quadro 9: (WORLD HEALTH ORGANIZATION, 2002).

\begin{tabular}{|c|l|}
\hline 1 & Perguntas abertas e objetivas \\
\hline 2 & Afirmação \\
\hline 3 & Escuta reflexiva \\
\hline 4 & Resumir \\
\hline $\mathbf{5}$ & Provocação de mudança de discurso \\
\hline
\end{tabular}

Quadro 8- As habilidades específicas da entrevista motivacional. Fonte: World Health Organization (2002). 
Perguntas abertas e objetivas são aquelas que requerem uma resposta longa e permitem que a pessoa fale. Exemplos desse tipo de questões são:

- Quais as coisas boas em relação ao seu uso do tabaco?

- $\quad$ Fale-me sobre as coisas que não são tão boas em relação ao uso de tabaco?

- Você parece ter alguma preocupação sobre o uso do tabaco. Fale-me mais sobre isso.

- Quais são suas preocupações sobre isso?

- Como você se sente em relação....?

- $\quad$ que você gostaria de fazer a respeito disso?

- $\quad$ O que você sabe sobre....?

Afirmação inclui declarações positivas e de compreensão, ajudando a criar uma atmosfera de apoio e a estabelecer vínculo com o paciente. Congratular-se com o esforço do paciente para a mudança ajuda a fortalecer sua confiança. São exemplos de afirmação:

- $\quad$ Obrigado por ter vindo hoje.

- Você está se esforçando para vencer suas dificuldades.

- $\quad$ Eu percebo que você é uma pessoa forte.

- Está é uma ótima ideia.

- $\quad$ É difícil falar sobre isso...eu admiro sua perseverança.

Uma escuta reflexiva leva a um entendimento do que o paciente sente. É importante devolver ao paciente o que ele expressou de significativo, como sentimentos, assim como as palavras que usou. É como um espelho para a pessoa para que possa ouvir do terapeuta o que ela falou. A escuta reflexiva encoraja o paciente a continuar falando e demonstra que o terapeuta entende o que está sendo dito. Alguns exemplos: 
- Você está se sentindo incomodado em falar sobre isso?

- Você está incomodado porque a sua família critica seu consumo do cigarro?

- Você realmente sente prazer em usar o cigarro e odiaria deixar de usar, mas também percebe que está lhe causando danos à saúde?

O Resumo é uma forma importante de juntar o que foi dito e preparar o paciente para a mudança. É importante fazer um resumo sucinto. Um exemplo:

"Você sente que é difícil parar de fumar porque isso relaxa e alivia sua ansiedade. Sem o cigarro, você passa mal, sente fissura e tem medo de engordar. Por outro lado, o filho pequeno te cobra, você está preocupado com os danos em sua saúde e se sente pressionado nos locais de trabalho em que não pode fumar. Você está se esforçando para encontrar algumas estratégias para cessar o consumo do tabaco".

Provocação de mudança de discurso é uma estratégia para ajudar o paciente a resolver a ambivalência e a estimulá-lo a apresentar argumentos para mudança. Existem quatro categorias de mudança de discurso:

- $\quad$ reconhecer as desvantagens de ficar na mesma situação;

- $\quad$ reconhecer as vantagens de mudança;

- $\quad$ expressar otimismo em relação à mudança;

- $\quad$ expressar uma intenção de mudança

Fazer perguntas abertas e diretas para trazer à tona o discurso de mudança, como por exemplo:

- $\quad$ O que você acha que aconteceria se você não mudasse?

- Quais seriam os benefícios se você diminuísse seu consumo do cigarro? 
- $\quad$ Como você gostaria que fosse sua vida daqui a cinco anos?

- O que você acha que aconteceria com você caso decidisse mudar o comportamento?

- $\quad$ O quanto confiante você está na sua capacidade de realizar essa mudança?

- Qual a importância para você de diminuir o uso do cigarro?

- $\quad$ Pense nas piores consequências de não mudar e as melhores consequências de mudar.

- Quais são as coisas mais importantes na sua vida?

\section{REFERÊNCIAS}

BORDIN, S.; FIGLIE, N.; LARANJEIRA, R. In: .et al. Aconselhamento em dependência química. São Paulo: Roca, 2004.

MILLER, W. R.; ROLLNICK, S. Entrevista motivacional: preparando as pessoas para a mudança de comportamento adictivos. Porto Alegre: Artmed, 2001.

OLIVEIRA, J. H.; MALBERGIER, A. Avaliação da motivação para tratamento em pacientes dependentes de álcool que procuram um serviço especializado. Rev. Bras. Psiquiatr., v.25, n.1, p.5-10, 2003.

PROCHASKA, J. O.; DICLEMENTE, C. Transtheorical therapy: toward a more integrative model of change. Psychotherapy: Theory, Research and Practice, Germantown, v. 20, n. 2, p. 161-173, 1982.

; DICLEMENTE, C. C.; NORCROSS, J. C. Search of how people change: Applications to addictive behaviors. American Psychologist, Washington, v.47, n.9, p.1102-1113, 1992.

ROLLNICK, S. MILLER, W.; BUTLER, C. Entrevista Motivacional no cuidado da saúde: Ajudando pacientes a mudar o comportamento. Porto Alegre: ARTMED, 2008. 
WORLD HEALTH ORGANIZATION. Brief interventions for substance use: a Manual for use in primary care. Geneva, 2002. Disponível em: <http:// www.who.int/substance_abuse/activities/assist_portuguese.pdf $>$ Acesso em: 5 dez. 2005.

ZIMMERMAN, G.; OLSEN, C.; BOSWORTH, M. A stage of change approach to helping patients change behavior. American Family Physician, Kansas City, v.61, n.5, p.1409-16, 2000. 